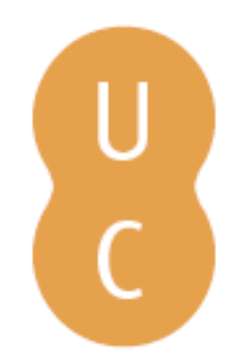

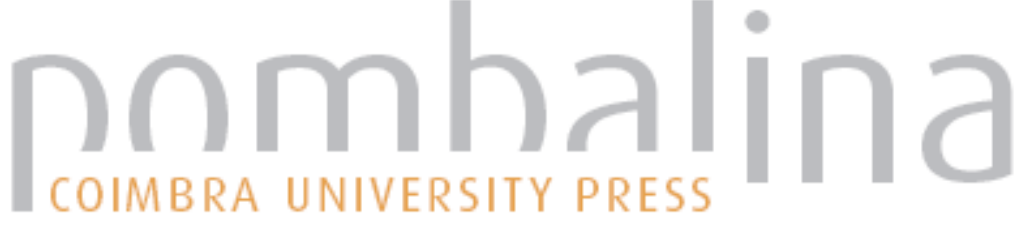

\section{Educar para a interculturalidade e cidadania: princípios e desafios}

\author{
Autor(es): Ramos, Natália
}

Publicado por: Imprensa da Universidade de Coimbra

URL

persistente: URI:http://hdl.handle.net/10316.2/31278

DOI: $\quad$ DOI:http://dx.doi.org/10.14195/978-989-26-0228-8_16

Accessed : $\quad$ 26-Apr-2023 10:31:33

A navegação consulta e descarregamento dos títulos inseridos nas Bibliotecas Digitais UC Digitalis, UC Pombalina e UC Impactum, pressupõem a aceitação plena e sem reservas dos Termos e Condições de Uso destas Bibliotecas Digitais, disponíveis em https://digitalis.uc.pt/pt-pt/termos.

Conforme exposto nos referidos Termos e Condições de Uso, o descarregamento de títulos de acesso restrito requer uma licença válida de autorização devendo o utilizador aceder ao(s) documento(s) a partir de um endereço de IP da instituição detentora da supramencionada licença.

Ao utilizador é apenas permitido o descarregamento para uso pessoal, pelo que o emprego do(s) título(s) descarregado(s) para outro fim, designadamente comercial, carece de autorização do respetivo autor ou editor da obra.

Na medida em que todas as obras da UC Digitalis se encontram protegidas pelo Código do Direito de Autor e Direitos Conexos e demais legislação aplicável, toda a cópia, parcial ou total, deste documento, nos casos em que é legalmente admitida, deverá conter ou fazer-se acompanhar por este aviso.

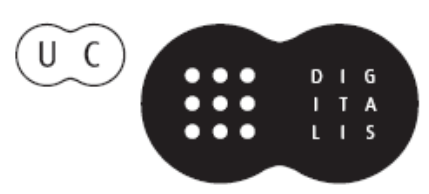




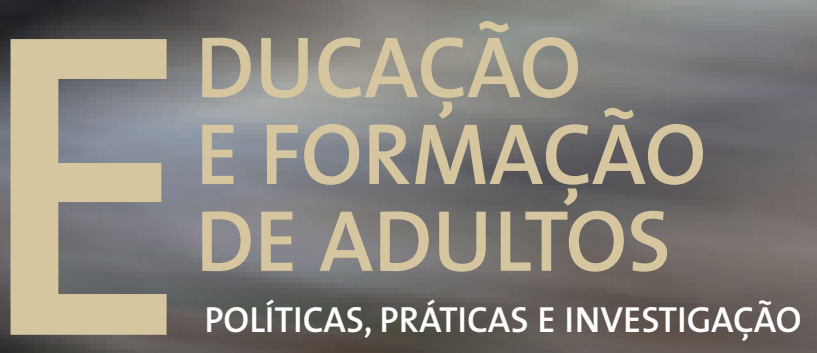

Luís Alcoforado • Joaquim Armando G. Ferreira António Gomes Ferreira • Margarida Pedroso de Lima Cristina Vieira • Albertina L. Oliveira • Sónia Mairos Ferreira 


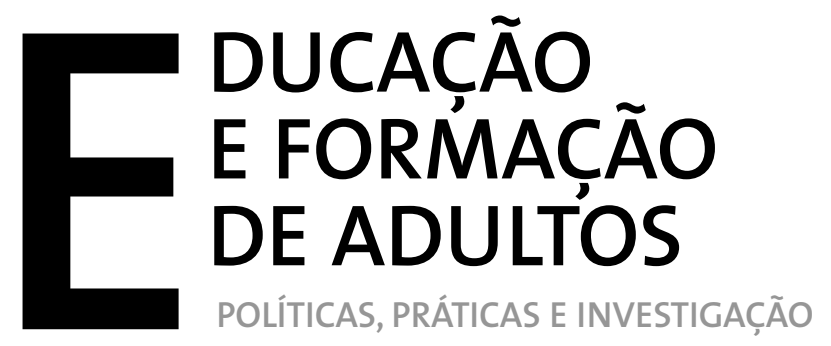

Luís Alcoforado • Joaquim Armando G. Ferreira António Gomes Ferreira - Margarida Pedroso de Lima Cristina Vieira • Albertina L. Oliveira • Sónia Mairos Ferreira 
EDIÇÃo

Imprensa da Universidade de Coimbra

URL: http://www.uc.pt/imprensa_uc

Vendas online: http://www.livrariadaimprensa.com

CONCEPÇÃO GRÁFICA

António Barros

Pré-Impressáo

SerSilito-Empresa Gráfica, Lda

EXECUÇÃo GRÁFICA

SerSilito-Empresa Gráfica, Lda

ISBN

978-989-26-0136-6

DePósito LEgaL

$340309 / 12$ 



\section{EDUCAR PARA A INTERCULTURALIDADE E CIDADANIA: PRINCíPIOS E DESAFIOS.}

Natália Ramos

Universidade Aberta

\section{Introdução}

$\mathrm{Na}$ atualidade, as questóes da multiculturalidade e das relaçôes interculturais são da maior importância no contexto do mundo globalizado, estáo no centro das preocupaçóes da maioria dos Estados, vindo colocar novos desafios, tanto à sociedade e às políticas do século XXI nos diferentes setores, em particular, nos domínios educacional, comunicacional e da saúde, como à gestão da diversidade e da comunicação intercultural.

A globalização e a crescente multiculturalidade que se verifica nos diferentes países e espaços da vida pública têm conduzido a esforços na reformulação de estratégias e políticas, com o objetivo de promover a integraçáo social, a educaçáo, o desenvolvimento e a comunicaçáo entre os diversos grupos e indivíduos que coabitam no mesmo espaço, assim como, a comunicação e a cooperação transnacional.

A diversidade intercultural, as relaçóes interculturais e a gestão da interculturalidade, são objeto de preocupação de vários organismos internacionais, tais como a UNESCO, a OCDE, o Conselho da Europa e a Comissão Europeia e constituem um dos campos mais importantes e atuais em diferentes domínios científicos, tanto ao nível da pesquisa, como ao nível da formação e da intervenção.

A diversidade cultural integra, cada vez mais, todos os domínios da esfera pública e esta diversidade deverá ser considerada, como destaca a UNESCO (2001), na Declaração Universal sobre a Diversidade Cultural, artigo 3: "[...] uma das fontes de desenvolvimento, entendido não só como crescimento económico, mas, também, como meio de acesso a uma existência intelectual, afetiva, moral e espiritual satisfatória".

A globalização e a interculturalidade têm vindo a questionar as identidades locais e "fechadas" de uma cultura nacional, tornando as identidades mais "abertas", plurais e híbridas. A cultura implica um processo permanente de construção e reconstrução, o qual, dados os crescentes movimentos migratórios atuais e contactos interculturais, têm tornado este processo extremamente dinâmico e interativo. Para Tourraine (2004) e Wiewiorka (2007), a cultura está no centro do que une e divide as sociedades contemporâneas.

O Conselho da Europa (2001) acentua que é necessário evitar os perigos e conflitos que podem resultar da marginalizaçáo daqueles que não possuem competências interculturais, para viverem e comunicarem num mundo multicultural, interativo e global.

Concordámos com Sandercock (2004), quando refere que o diálogo intercultural tem de estar presente no quotidiano e assente em dois tipos de direitos fundamentais:

- o "direito à cidade", enquanto espaço coletivo, promotor da participação e de integração de todos na vivência da cidade; 
- o "direito à diferença", enquanto promoção e valorização da diversidade, da comunicação intercultural e da alteridade.

O confronto com a diversidade e a alteridade, o encontro intercultural, as relaçóes entre o Eu e o Outro, são influenciados por representaçóes sociais, por estereótipos, preconceitos, projeçôes culturais, ideológicas e políticas. Estes elementos vão ter importância, quer na aceitação/inclusão do Outro, quer na discriminação/exclusão da diferença, do estrangeiro; quer na anulação ou valorização da identidade do Outro e da alteridade, quer, ainda, no desenvolvimento e bem-estar ou no sofrimento e doença.

O Outro poderá ser visto como alguém a tolerar, como um sujeito pleno de um grupo social, como uma fonte social e cultural positiva, como um cidadão com direito à afirmação da diferença e à participação, ou como ameaça e fonte do mal e um sujeito a excluir, a discriminar ou a eliminar.

As relaçóes entre indivíduos e grupos culturalmente diferentes originam um conjunto complexo de representaçóes e processos psicológicos e sociais, tal como salienta Moscovici (2005: 56): "Pessoas que pertencem a outras culturas nos incomodam, pois estas pessoas sáo como nós e, contudo, não são como nós; assim, nós podemos dizer que elas são "sem cultura", "bárbaros"," irracionais", etc (...) O "não familiar" atrai e intriga as pessoas e comunidades (...) $O$ medo do que é estranho (ou dos estranhos) está profundamente arraigado em cada um de nós".

De igual modo, os membros de uma cultura tendem a considerar as suas práticas e símbolos superiores aos das outras culturas, como já referia o filósofo francês do século XVIII Montesquieu (1748, II, 9, V.1): "Se percorrer todas as naçôes, encontrarei por todo o lado hábitos diferentes e cada povo acreditará que os seus costumes são os melhores".

Estas representações, estas imagens deverão ser reconhecidas na sua subjetividade e objetividade, nas suas implicaçóes individuais e coletivas, no espaço e no tempo, na experiência do Eu e do Outro. Deverão ser situadas nos contextos psico-socio-históricos de origem, nos contextos simbólicos e reais, implicando a análise das suas funçôes na identidade e alteridade, na dinâmica das relaçóes entre os indivíduos, as culturas e as sociedades e, ainda, ao nível da coesão social e do desenvolvimento dos indivíduos e dos grupos.

\section{Contextos da Multi/Interculturalidade - Figuras do Outro e da Alteridade}

O aumento da globalização e dos fluxos migratórios no mundo, em particular na União Europeia, fizeram aumentar a multi/interculturalidade nas sociedades e a coabitação com a diversidade cultural, com o Outro. Tem-se vindo a assistir no mundo a uma intensificação da diversidade cultural e a uma afirmação das diferenças.

No mundo aberto e plural de hoje, com a globalização e os novos meios de comunicação, com os media, a internet, as facilidades de deslocação e os meios de transporte rápidos, a diversidade cultural e o Outro têm hoje um outro estatuto e imagem. O Outro não está longínquo e distante, mas está mais próximo e presente no quotidiano e, ainda que nem sempre aceite e compreendido, coabita connosco e reclama respeito e direitos. Temos assim uma diversidade cultural que encontramos no seio dos Estados, das cidades, no dia-a-dia, relacionada com a abertura ao mundo, a globalização e a cidadania.

Temos o estatuto do Outro no quadro das migraçóes, da globalização e da Convenção da UNESCO (2001, 2005, 2007), reconhecendo a igualdade das culturas e constituindo uma revolução democrática, no plano internacional. A primeira figura do Outro e da diver- 
sidade cultural é o Migrante, aquele para quem a migração poderá aumentar a liberdade, as oportunidades de decisão e o poder de escolha, melhorar as condições de vida, alargar o acesso aos serviços básicos, à escolaridade, à saúde e à participação e constituir um fator importante de desenvolvimento, se lhe for proporcionado acolhimento e contextos social, educacional e político adequados. Todavia, este Outro é, frequentemente, ignorado e/ou discriminado, sobretudo o migrante pobre, objeto de medos e exclusão, símbolo de ameaça e da diversidade cultural recusada na prática, ainda que defendida nos textos.

Os migrantes são, por vezes, confrontados com fronteiras de identidade e de memória, com fronteiras de preconceito, de violência e de racismo, que os conduzem a situaçóes de sofrimento, desilusão e mau estar, as quais podem afetar a sua identidade, integração, saúde e capacidade para reclamar e defender os seus direitos. Para muitos migrantes, não são os sonhos de uma vida melhor, nem os motivos políticos ou privados de quem atravessa fronteiras ou continentes que, frequentemente, aparecem nas representaçōes ou nas campanhas que os discriminam ou condenam. Muitas histórias de mobilidade, migração e exílio caraterizam-se pela violência exclusionista, ou assimiladora, representando uma violência estrutural e estruturante, que se acompanha de dispositivos simbólicos que criam fronteiras de separação entre "bons" e "maus", entre "cidadãos" e "bárbaros/estranhos", entre "nós" e os "outros". Estes dispositivos originam processos de ocultação da violência e inversão de causalidade, projetando a culpa para as vítimas (Farmer, 2003). Contudo, no mundo globalizado de hoje, os indivíduos continuam a migrar, dentro ou para fora dos seus territórios, em busca de melhores perspetivas e condiçôes de vida. Estas deslocaçóes deverão ser consideradas como um direito humano, tal como é consagrado no artigo $13^{\circ}$ da Declaração Universal dos Direitos Humanos, adoptada em 1948 pela Organizaçáo das Naçóes Unidas (ONU): "Todo o indivíduo tem o direito de circular livremente e escolher a sua residência no interior de um Estado. Todo o individuo tem o direito de abandonar o país em que se encontra, incluindo o seu, e o direito de regressar ao seu pais".

A migração ocorre, sobretudo no interior dos países, estimando-se que haja aproximadamente 740 milhóes de migrantes internos e 214 milhóes de migrantes internacionais. Dos migrantes internacionais, cerca de 100 milhões são mulheres, constituindo a feminização das migraçóes uma das caraterísticas das migraçóes atuais. São os continentes europeu e asiático os que acolhem no seu território o maior número de migrantes, respectivamente 69,8 milhôes e 61,3 milhóes de pessoas. Os EUA constituem o país que acolhe o maior número de migrantes, ou seja, 42,8 milhóes (ONU, 2011). Os que migram devido à insegurança, catástrofes ou guerra são cerca de 14 milhóes e representam $7 \%$ dos migrantes no mundo.

Em Portugal, a população de origem estrangeira totaliza 445262 cidadãos, constituindo a comunidade brasileira a maior população estrangeira residente em Portugal (119 363), correspondendo a $25 \%$ da comunidade estrangeira residente no país (SEF, 2010).

O Instituto Nacional de Estatística (INE, 2009) destacava que, em 2008, nasceram em Portugal 13802 crianças em que um, ou ambos os pais eram estrangeiros, reunindo 13\% da totalidade dos nascimentos neste ano, sendo os brasileiros os que contribuem com o maior número de crianças e que se mantêm em primeiro lugar, na união com portugueses.

Em Portugal, no ano letivo de 2008/2009, estavam inscritos nas escolas portuguesas do ensino básico e secundário 70508 alunos de origem estrangeira, divididos por 90 nacionalidades, sendo as mais representativas, Brasil e Cabo Verde, segundo dados do Ministério da Educação (GEPE). 
De acordo com o Observatório Português da Ciência e do Ensino Superior - OCES, em Portugal, o número de estudantes estrangeiros inscritos no ensino superior tem vindo a aumentar nos últimos anos, tendo-se registado um crescimento de $65,7 \%$, só entre os anos letivos de 1999/2000 e 2004/2005. Neste ano letivo, 17594 estrangeiros estavam inscritos no ensino superior público e privado português, sendo a maioria de Angola (4 258), Cabo Verde (3 835) e Brasil (1 796).

A diversidade cultural está, igualmente, representada nos cerca de 3 milhóes de estudantes de ensino superior, que se encontram fora dos seus países, situando-se o aumento dos estudantes internacionais em 41\%, só entre 1999 e 2004 (OCDE, 2009).

$\mathrm{Na}$ União Europeia, no quadro do programa de mobilidade ERASMUS, programa a funcionar desde 1987, já são mais de um milhão e seiscentos mil (1 683 928), os estudantes universitários que, entre 1987 e 2007, frequentaram outras instituiçóes de ensino superior de um dos trinta e dois países europeus participantes neste programa. Em 2008/2009, 5 398 estudantes portugueses participaram no Programa ERASMUS, sendo os países mais escolhidos a Espanha e a Itália. Neste mesmo ano escolar, Portugal acolheu um total de 6 234 estudantes no âmbito deste programa vindos, sobretudo, de Espanha.

No quadro do ERASMUS MUNDUS, calcula-se que 1300 alunos de fora da Europa vieram estudar, ao abrigo deste programa. Este aumento da mobilidade internacional estudantil e as alteraçóes realizadas no Ensino Superior na Europa vão ao encontro da Declaração de Bolonha e reforçam a criação de um Espaço Europeu e Mundial de Ensino Superior e a promoção das relaçóes interculturais ao nível estudantil.

Outra figura do Outro e da diversidade cultural está associada à cidade, à urbanização, àquele que habita a cidade e os seus arredores. Com efeito, mais de metade da populaçáo mundial (65\%), oriunda de diversos universos culturais e sociais, habita hoje em zonas urbanas e suburbanas, prevendo-se que, em 2030, as cidades do mundo em desenvolvimento acolham $80 \%$ do total da população, contribuindo as migraçóes para este aumento populacional.

Outra figura de diversidade cultural e do Outro são os cerca de 300 milhóes de pessoas, distribuídas por mais de 70 países, que pertencem a grupos indígenas, representando cerca de 4000 línguas. $\mathrm{Na}$ América Latina, por exemplo, os 50 milhóes de indígenas constituem $11 \%$ da população da região (PNUD, 2004).

Também, a União Europeia, projeto político que envolve 27 países e 500 milhôes de habitantes com história e língua diferentes (26 línguas) e com identidades sociais e culturais fortes, constitui um grande desafio político, cultural, educacional, comunicacional e, em particular, um desafio à diversidade cultural, ao diálogo intercultural e à coabitaçáo cultural.

Neste sentido, o Conselho da Europa e a Comissão Europeia insistem em que é necessário promover a "Cidade Aberta e Intercultural" e acolher a diversidade cultural nas cidades ditas "globais", de modo a responder às novas dinâmicas e necessidades das sociedades atuais (Sassen, 2001).

\section{Convenção Cultural da UNESCO e Paradigma Intercultural}

A UNESCO tem-se preocupado em reconhecer a igualdade de todas as culturas e em definir a diversidade cultural, tendo-se esta constituído como uma questáo política e um conceito institucionalizado de política internacional. 
A diversidade cultural é reconhecida pela UNESCO $(2001,2005,2007)$ como uma "caraterística inerente à humanidade", como um "património comum" e como uma fonte de "um mundo mais rico e diversificado que alarga a possibilidade de escolhas e fortalece as capacidades e os valores humanos."

A adoção, em 20 de Outubro de 2005, pela UNESCO, da "Convenção para a Proteção e Promoção da Diversidade das Expressóes Culturais” representa uma etapa fundamental para a emergência do direito cultural internacional. Esta Convenção constitui o primeiro documento internacional, com valor jurídico, a estatuar sobre a importância da cultura e da diversidade cultural, no domínio das políticas culturais, mas, também, no âmbito da cooperaçáo internacional, do desenvolvimento e dos direitos humanos.

A convenção da UNESCO concilia a defesa de duas visôes:

- do universalismo, com a defesa dos valores universais da paz, da solidariedade, da justiça e dos direitos do homem;

- do particularismo, com a liberdade de cada um expressar a sua cultura e decidir as suas escolhas.

Esta Convenção tem por objetivo criar condiçôes que permitam às culturas desenvolverem-se e interagirem abertamente, de modo a um enriquecimento mútuo, pertencendo aos Estados, em colaboração com a sociedade civil, intervirem através de açóes concretas a diferentes níveis: ao nível nacional (através dos governos); ao nível internacional (através do controlo coletivo dos Estados signatários); ao nível nacional e transnacional (através da sociedade civil).

A crescente mobilidade populacional e cooperaçáo transnacional proporcionam o contacto de grande diversidade de culturas e identidades, vindo colocar desafios às populaçóes autóctones e migrantes e às relaçóes interculturais e exigir um novo paradigma na pesquisa e intervenção, que designámos de Paradigma Intercultural.

A reflexão sobre a diversidade cultural, através deste paradigma, implica processos dinâmicos e multidimensionais (Bierbrauer \& Pedersen, 1996) e reenvia aos conceitos de reciprocidade, de complexidade (Morin, 1990), de complementaridade (Devereux, 1992) e de facto social total (Mauss, 1950, Mead, 1950).

O Paradigma Intercultural vem desafiar os paradigmas tradicionais e implica várias constataçóes e perspetivas:

- uma constatação de ordem sociológica, tendo em conta que a maioria das nossas sociedades são e serão cada vez mais multiculturais;

- uma opção de ordem ideológica, já que a multi/interculturalidade é, potencialmente, uma riqueza para o conjunto da sociedade;

- uma visáo estratégica, tendo em conta que para passar do multiculturalismo ao interculturalismo, torna-se necessário promover a relação entre as culturas, sem, no entanto, anular a identidade de cada uma delas;

- uma perspetiva multi/interdisciplinar, na medida em que os objetos do domínio intercultural são objetos complexos, plurais, heterogéneos e pluridimensionais, que não podem ser reduzidos a uma única abordagem disciplinar;

- uma perspetiva sistémica e multidimensional, necessária a uma visão global, integrativa e interacionista da complexidade e da diversidade e à construção de um pluralismo 
comum, implicando, ao mesmo tempo, o reconhecimento dos indivíduos e das culturas e a integração das representaçóes, práticas, políticas e contextos;

- um processo dinâmico e dialético, onde o intercultural exige a tomada de consciência da alteridade e da diversidade, das identidades individuais e coletivas, das interaçóes entre os indivíduos e os grupos e, ainda, das relaçóes entre o Eu e o Outro;

- uma perspetiva psicossocial e pedagógica, visto que as problemáticas interculturais implicam o desenvolvimento de competências culturais, sociais, pedagógicas, comunicacionais, de competências individuais e de cidadania, que permitam interaçóes sociais harmoniosas entre os indivíduos e as culturas e que promovam a consciencialização cultural, a comunicaçáo intercultural e o funcionamento democrático das sociedades;

- uma perspetiva sociopolítica, tendo em conta, que o interculturalimo não é somente um objetivo em si, mas, também, um instrumento para promover a coesáo social, o exercício da cidadania, a igualdade de oportunidades e uma integração adequada da diversidade cultural e das minorias.

O paradigma intercultural vem introduzir a pluralidade, a heterogeneidade, a complexidade e a multi/interdisciplinaridade na pesquisa, formação e intervenção, implicando um novo reposicionamento metodológico, epistemológico e ético, assente em três vertentes estruturantes:

Concetual - As diferenças culturais são definidas, não como elementos objetivos com caráter estático, mas como entidades dinâmicas e interativas, que se dão sentido mútuo. A abordagem intercultural constitui uma outra forma de analisar a diversidade cultural, não a partir das culturas consideradas como entidades independentes e homogéneas, mas a partir de processos e de interaçóes;

Metodológica - A abordagem intercultural define-se como global, multidimensional e interdisciplinar, de modo a dar conta das dinâmicas e da complexidade dos fenómenos sociais e a fim de evitar os processos de categorização. Trata-se, para o investigador/educador/ interveniente, de adquirir familiaridade com o universo social sobre o qual trabalha, de compreender as representaçóes que o animam e de se interrogar de forma reflexiva, não só sobre a cultura do outro, mas, também e em primeiro lugar, sobre a sua própria cultura;

Ética - A perspetiva intercultural tem como objetivo o conhecimento das culturas, mas, sobretudo, a relação entre elas e ao Outro, implicando uma atitude de descentraçáo (Piaget, 1970). Envolve uma reflexão sobre a forma de respeitar a diversidade individual, social e cultural, de conciliar o universal e o particular, o global e o local, de adaptaçáo à complexidade estrutural duma sociedade e à sua conflitualidade.

\section{Diversidade Cultural e Competências Interculturais}

Viver, trabalhar, comunicar e educar em contexto multicultural exige o desenvolvimento de um conjunto diversificado de competências. Estas competências do domínio intercultural podem agrupar-se deste modo:

- competências individuais, que permitam interaçóes sociais harmoniosas entre os indivíduos e as culturas e que promovam uma atitude de descentração, a qual permitirá flexibilizar e relativizar princípios, modelos e competências apresentados como únicos e universais e evitar muitos comportamentos de intolerância, discriminação e exclusão; 
- competências interculturais, sobretudo linguísticas, comunicacionais e pedagógicas, que facilitem, por um lado, a comunicação intercultural e a consciencialização cultural e, por outro, que promovam uma educação e intervenção interculturalmente competentes e inclusivas e profissionais e cidadãos culturalmente sensíveis e implicados;

- competências de cidadania, que tornem possível o funcionamento democrático das sociedades e das instituições.

Como sugere Vygotsky (2001, p. 27): "A função primordial da linguagem é a comunicação". Existindo no mundo perto de 6.000 línguas (Nodari \& Shander, 2006) e constituindo a língua o principal meio de comunicação e de acesso a uma cultura, o ensino das línguas desempenha um papel fundamental na educação e comunicação intercultural e na educação para a cidadania.

A língua é um instrumento fundamental para a comunicação e para a integração das diversas culturas e grupos minoritários, que habitam no mesmo espaço territorial. Neste contexto, o ensino/aprendizagem da língua segunda permite aos que vivem, estudam ou trabalham num país que não é aquele onde têm a nacionalidade, a sua integração na cultura e na sociedade maioritária.

Popovici (2006) acentua a importância do ensino das línguas e da preparação dos alunos para "viver em conjunto", com o objetivo da prevenção e resolução de conflitos e para promover a comunicação intercultural.

Vai neste sentido o pensamento de Morin (2001, p. 17), quando salienta a importância do ensino da compreensão mútua entre os seres humanos, quer próximos, quer "estranhos", daí a "necessidade de estudar a incompreensão a partir das suas raizes, suas modalidades e seus efeitos. Este estudo é tanto mais necessário porque enfocaria, não os sintomas, mas as causas do racismo, da xenofobia, do desprezo".

Uma pedagogia da relação intercultural, baseada na compreensão, no respeito e reconhecimento do Outro e da diversidade, deverá ajudar cada um a determinar as suas próprias representações, preconceitos, estereótipos e modelos do seu sistema de valores. Deverá, igualmente, ajudar a identificar as representaçôes, preconceitos, estereótipos e sistemas de valores dos outros indivíduos e grupos, constituindo um meio de aprendizagem de si mesmo e do Outro, de compreensão intercultural, de luta contra o etnocentrismo, a discriminação e a xenofobia.

O etnocentrismo, os estereótipos e os preconceitos constituem barreiras, filtros culturais à comunicação intercultural e estão na origem de conflitos e incompreensão entre grupos minoritários e maioritários (Samovar \& Porter, 1988, Ladmiral \& Lipiansky, 1992, Cohen-Emerique, 1993).

No confronto com a diferença e a diversidade, é importante ter em conta o etnocentrismo, constituindo este um dos principais fatores que determinam o impacto psicológico do indivíduo face a um novo meio. Os indivíduos etnocêntricos utilizam os seus valores e modelos para julgar os outros, os objetos e os acontecimentos, considerando as outras perspetivas culturais como inferiores, incorretas ou imorais, em comparaçáo com as suas (Triandis, 1990).

O etnocentrismo origina distância social, ódio, desconfiança, medo e discriminação do exogrupo, em relação ao endogrupo. A intensidade do etnocentrismo varia segundo as culturas, o tempo, o espaço e os indivíduos, no seio de uma mesma cultura, havendo, contudo, um certo nível de etnocentrismo que se apresenta como universal (Levine \& Campbell, 1972). 
Para desenvolver a competência na comunicação e nas relaçóes interculturais, é importante a tomada de consciência do grau de determinismo cultural dos nossos comportamentos, é necessário desenvolver a consciencialização cultural. Esta constitui um processo de aprendizagem cultural, que visa desenvolver a capacidade de analisar o mundo do ponto de vista de uma outra cultura e as competências para reconhecer as diferenças e a pluralidade (Hoopes, 1980).

Para desenvolver competências no domínio intercultural e a compreensão recíproca entre indivíduos, grupos e culturas, é importante:

- aprender a conhecer-se a si mesmo e à sua própria cultura;

- aprender a descobrir e a compreender o sentido de normas e valores, os quadros de referência dos outros e os códigos culturais respetivos;

- evitar julgamentos rápidos e superficiais, estereótipos, preconceitos e atitudes etnocêntricas, o que permitirá colocar-se no lugar do outro, de forma a tentar compreender as coisas do seu ponto de vista, o que permitirá a descentração. A atitude e a prática da descentração dá-nos a capacidade de relativizar e de visualizar uma situação através de várias perspetivas e de outros quadros de referência, ajuda cada um a adotar uma certa distância em relaçáo a si mesmo e conduz à autoreflexão, constituindo uma das atitudes que todos os profissionais, particularmente os educadores, deverão trabalhar em permanência;

- desenvolver a empatia, o que implica a capacidade de se colocar no lugar do Outro e o reconhecimento do Homem na sua individualidade e singularidade;

- dispor de tempo para comunicar, para compreender uma situação, estar atento às mensagens silenciosas da comunicação não verbal, ter em conta o contexto físico, social e humano onde se desenrola a comunicação, assim como aprender a respeitar os ritmos e os estilos de comunicação próprios de cada indivíduo e de cada cultura;

- desenvolver estratégias e intervençôes psicossociais e educativas interculturais, incluindo uma formação centrada sobre a cultura dos diferentes grupos e comunidades presentes no mesmo espaço educacional ou social, e nas relaçóes interculturais, por exemplo, desenvolver projetos de educação para a diversidade (Ramos, 1997, 1998);

- implementar uma formação adequada dos professores e uma revisão dos programas e dos materiais didáticos;

- respeitar a diversidade linguística e as línguas maternas e promover a aprendizagem da segunda língua e das línguas estrangeiras;

- trabalhar os currículos e os materiais de aprendizagem, sobretudo os que apresentam mensagens discriminatórias e "racistas", utilizando-os como instrumentos de consciencialização intercultural;

- utilizar adequadamente os meios de comunicação social, em particular os media audiovisuais, nomeadamente, na sensibilização à interculturalidade e no combate aos preconceitos, estereótipos e a todas as formas de discriminação;

- aprender a construir projetos e a encontrar soluçóes em conjunto para a resolução de conflitos e para a compreensão das relaçóes interculturais e de interdependência cada vez maiores;

- aprender a dialogar com as outras culturas e aceitar negociar e propor compromissos, de modo a evitar comportamentos de rejeição ou de assimilação;

- desenvolver uma formação que explique e contribua para a compreensão da diversidade cultural e dos preconceitos e estereótipos socialmente construídos em relação às 
minorias e às diferenças religiosas, sociais, étnico/culturais, geracionais e de género, assim como, dos procedimentos para combatê-los, de modo a favorecer a alteridade e as expetativas positivas em relaçáo às minorias;

- fomentar uma melhor compreensão dos mecanismos psicossociais e dos fatores sociopolíticos suscetíveis de originar a intolerância, a rejeição e a xenofobia;

- desenvolver competências tecnológicas, nomeadamente ao nível do domínio e utilização das novas tecnologias de informação e comunicação (TIC) e da internet, as quais vêm, através da inclusão digital, favorecer a comunicação intercultural, a inclusão social, a educação transnacional, a democratização do ensino e viabilizar encontros virtuais que facilitam o contacto e partilha de ideias e recursos de informação e aprendizagem, disponíveis em qualquer parte do mundo;

- proporcionar informação e formação, em relação à negociação dos conflitos à escala nacional e internacional, de cariz social, económico, político e cultural ou ainda, sobre conflitos entre valores fundamentais (atentados aos direitos humanos, formas de discriminaçáo e violência, por exemplo, pobreza e desigualdades sociais, mutilaçóes genitais...).

Para preparar os indivíduos para as relaçóes interculturais, têm sido desenvolvidos diversos programas de formação e treino de competências interculturais, por numerosos investigadores e educadores, em diferentes países do mundo (Landis e Brislin, 1983, Black e Mendenhall, 1990, Brislin, 1993, Brislin e Yoshida, 1994, Cohen-Emerique, 1993, 1999, Filtzinger, 1999, Demorgon, 2000).

Muita da formação em interculturalidade, ao nível da intervenção social, valoriza as culturas de origem e as de acolhimento, tentando articulá-las, assim como as relaçóes intergeracionais, de modo a evitar os choques interculturais e geracionais e a facilitar a resolução de conflitos, desenvolvendo formaçóes sobre a interculturalidade e as problemáticas migratórias, de forma pluridimensional e pluricultural (Cohen-Emerique, 1993, 1999, Filtzinger, 1999).

Através da avaliação da importância e eficácia desta formação/treino, o qual poderá utilizar várias técnicas que poderão ir da informação e formação intercultural, da sensibilização cultural, ao role playing e aprendizagem experiencial, constatou-se que, na maioria dos estudos, os indivíduos reconheceram que o seu treino/formação intercultural tinha sido positivo e eficaz, com melhorias na realização e com diminuição do stress de aculturação (Black e Mendenhall, 1990).

Landis e Brislin (1983) e Brislin (1993) consideram que os contactos entre as culturas e as relaçóes interculturais tenderão a aumentar e que a pesquisa e treino intercultural poderáo dar orientaçóes e contributos positivos, para as relaçóes interculturais. Para estes autores, um bom treino intercultural deverá: ter em conta os pensamentos, sentimentos e comportamentos dos indivíduos, contribuindo para a consciencializaçáo das atitudes e opiniôes culturais; ajudar na promoção da aceitação de comportamentos diferentes ou considerados estranhos e na modificação de atitudes e comportamentos, de modo a ir ao encontro e compreender as expetativas dos indivíduos de outras culturas e as suas lógicas culturais; fornecer informação sobre os outros países e promover a aprendizagem experiencial, pela imersão noutro país e noutra cultura.

Através de uma revisáo da literatura, Brislin e Yoshida (1994) destacaram um conjunto de benefícios do treino e formação intercultural, nomeadamente: maior capacidade para 
lidar com as diferenças culturais; mais bem-estar e satisfação nas relaçôes interculturais; diminuição do stress e melhoria nas relaçóes interpessoais e no trabalho com grupos heterogéneos; maior abertura ao mundo e à alteridade; maior capacidade para resolver problemas que exigem a compreensão cultural, a relação com outras culturas e a adaptação à mudança.

\section{Consideraçôes Finais}

Estamos de acordo com Wolton (2003), quando assinala que "Aprender a gerir a diversidade cultural constitui a verdadeira riqueza das sociedades futuras".

A aquisição e o desenvolvimento de competências interculturais são objetivos fundamentais para fazer face à diversidade e complexidade que caraterizam o tecido social atual e para a educação das crianças, jovens e adultos e dos cidadãos, em geral.

É necessário solidificar os quatro paradigmas da educação para o século XXI defendidos por Delors (1996), ou seja: aprender a ser; aprender a conhecer; aprender a fazer; aprender a viver juntos.

Como salienta a UNESCO (2001), a educação para formar os cidadãos do século XXI, o século da (s) interculturalidade (s) e da (s) cidadania (s) deverá promover: o conhecimento e respeito da diversidade cultural e a comunicaçáo intercultural; o acesso na igualdade e equidade; a aprendizagem ao longo da vida; a solidariedade nacional e internacional; a formação de cidadãos, não só nacionais, mas também do mundo; uma cultura humanista que inscreva os homens e as mulheres no mundo e na tomada de consciência do destino comum a todos os Homens.

A pluralidade e a heterogeneidade dos mundos contemporâneos exigem aprender a viver a multiplicidade de pertenças e de referências, não sob a forma de dicotomias, de exclusividade e de exclusão, mas de um modo plural, contínuo e complementar.

O objetivo da interculturalidade não é a separação do universal e do particular, mas a reunião, ou seja, a organização de um contexto social e relacional integrativo que tenha em conta um processo dialético ligando o Eu e o Outro, a abertura ao mundo e o reconhecimento das identidades e da alteridade.

É importante um paradigma de abordagem da diversidade cultural e dos grupos minoritários, não como um problema, mas como um recurso de capacitação e revalorização de identidades culturais e de cidadania, uma oportunidade de desenvolvimento individual, social e cultural e um processo de educação e resiliência. Isto, de modo a fortalecer as competências dos indivíduos e dos grupos para se consciencializarem dos seus direitos e deveres e para enfrentarem a mudança e o seu próprio desenvolvimento, integração e destino, de uma forma positiva e participativa.

A perspetiva intercultural, a diversidade e alteridade deverão ser integradas numa perspetiva mais ampla de construção da sociedade e de igualdade de oportunidades, devendo estar no centro do processo educativo e do desenvolvimento humano e social, sendo importante que se faça da diversidade cultural, da mobilidade e das relaçóes interculturais, um desafio e oportunidade de enriquecimento e de comunicação ao ritmo de um mundo global e de uma sociedade aberta, plural e solidária, partilhando tradiçóes culturais, espaços, competências e recursos.

Como salienta Delors (1996), "é necessário assumir a diversidade e a multipertença como uma riqueza. A educação à pluralidade é não só uma proteção contra a violência, mas também um princípio ativo de enriquecimento cultural e cívico das sociedades contemporâneas". 


\section{Referências Bibliográficas}

Abdalhah-Pretceille, M. (1986). Vers une pédagogie interculturelle. Paris, Pub. De la Sorbonne.

Bierbrauer, G., Pederson, P. (1996). Culture and migration. In G. Semin e K. Fiedler (eds). Applied social psychology. (pp. 399-422). London: Sage.

Black, J., MendenhalL, M. (1990). Cross-cultural training effectiveness: a review and theoretical framework for future research. Academy of Management Review. 15, 113-136.

Brislin, R. (1993). Understanding culture's influence on behavior. San Diego: Harcourt Brace College Publishers.

Brislin, R. \& Yoshida, T. (1994). Intercultural communication training: an introduction. Thousand Oaks, CA, Sage.

Camilleri, C. (1999). Principes d'une pédagogie interculturelle. In J. Demorgen et E. M. Lipiansky (Dir.) Guide de l'interculturel en formation. Paris, Ed. Retz: 208-218.

Candominas, C. (1999). L'immersion est-elle une formation à l'interculturel. L'exemple du Japon. In J. Demorgon e E. Lipiansky. Guide de l'interculturel en formation. Paris: Retz.

Clanet, C. (1990). L'interculturel. Introduction aux approches interculturelles en education et en sciences humaines. Toulouse: Presses Universitaires du Mirail.

Cohen-Emerique, M. (1993). Travailleurs sociaux et interculturel: quelle démarche? F. Grong-Dahmane (Ed.). Enfants d'ici, enfants d'ailleurs. Ramonville Sainte-Agne: Érés.

Cohen-Emerique, M. (1999). La formation des formateurs et des travailleurs sociaux. In J. Demorgon e E. Lipiansky. Guide de l'interculturel en formation. Paris: Retz.

Conselho da Europa (2000). Diversity and cohesion: new challenges for the integration of immigrants and minorities. Strasbourg: Pub. do Conselho da Europa.

Delors, J. et al. (1996). Educação: um tesouro a descobrir. Relatório para a UNESCO. Comunicação Internacional sobre a Educação para o Século XXI. Porto: Editora ASA.

Demorgon, J. (2000). L interculturation du monde. Paris: Anthropos Economica.

Devereux, G. (1992). Ethnopsychanalyse complémentariste. Paris: Flammarion.

Farmer, P. (2003). Pathologies of power: health, human rights and the new war on the poor. Berkeley: University of California Press.

Filtzinger, O. (1999). Transformer les programmes de formation. In J. Demorgon e E. Lipiansky. Guide de l'interculturel en formation. Paris: Retz.

Hoopes, D. (1979). Intercultural Communication concepts and the psychology of intercultural experience. In M. Pusch, Multicultural education: a cross cultural training approach. Chicago: Network, Inc.

Ladmiral, J. R. \& Lipiansky, E. M. (1992). La communication interculturelle. Paris: A. Colin.

Landis, D. \& Brislin, R: (eds), (1983). Handbook of intercultural training. New York: Pergamon.

Levine, R. \& Campbell, D. (1972). Ethnocentrism. New York: Wiley.

Mauss, M. (1950). Sociologie et Anthropologie. Paris: PUF.

Mead, M. (1955), (ed). Childhood in contemporary cultures. Chicago: Chicago University Press.

Montesquieu (1748). De l'esprit des lois. II, 9, V. 1. Paris: Ed. Gallimard.

Morin, E. (1990). Introduction à la pensée complexe. Paris: ESF.

Morin, E. (2001). Os sete saberes necessários à educação do futuro. São Paulo: Cortez.

Moscovici, S. (2005). Representaçôes Sociais. Investigação em Psicologia Social. Petropólis: Ed. Vozes.

Nodari, C. \& Schader, B. (2006). L'allemand comme deuxième langue/langues de la migration: les tenants et les aboutissants d'un nouveau domaine à la Haute Ecole Pédagogique de Zurich. In Akkari, A .J. et al. Approches interculturelles dans la formation des enseignants: impact, stratégies, pratiques et expériences. Neuchâtel, CDHEP, 4, 163-172.

Ouellet, F. (1991). L 'éducation interculturelle. Essai sur le contenu de la formation des maîtres. Paris: L'Harmattan.

Pnud (2004). Relatório do Desenvolvimento Humano. Liberdade cultural num mundo diversificado. Lisboa: Ed. Mensagem.

Popovici, R. (2006). Integration of citizenship, human rights and language education. In Fenner, A., Newby, D. (Org.). Coherence of principles, cohesion of competences. Estrasbourg: Council of Europe, 59-68.

Ramos, N. (1997). (Cord). Educar para a Diversidade - Timor Oriental. Versão em Língua Francesa, inglesa e portuguesa. Prod. Scripto, Audio e Video. Lisboa: Universidade Aberta.

Ramos, N. (1997). (Cord). Educar para a Diversidade - Cabo Verde. Versão em Língua Francesa, inglesa e portuguesa. Prod. Scripto, Audio e Video. Lisboa: Universidade Aberta.

Ramos, N. (1998). (Cord). Educar para a Diversidade - Goa. Versão em Língua Francesa, inglesa e portuguesa. Prod. Scripto, Audio e Video. Lisboa: Universidade Aberta.

Ramos, N. (2001). Comunicação, cultura e interculturalidade: Para uma comunicação intercultural. Revista Portuguesa de Pedagogia, 35 (2), 155-178. 
Ramos, N. (2002). Communication, éducation et interculturalité. Vers une éducation à la tolérance. Dialogos, (5), 68-75.

Ramos, N. (2003). Interculturalité, communication et education. Bucareste: Ed. Melina Press.

Ramos, N. (2007). Sociedades Multiculturais, Interculturalidade e Educação. Desafios Pedagógicos, Comunicacionais e Políticos. Revista Portuguesa de Pedagogia. 41 (3), 223-244.

Ramos, N. (2008). A diversidade cultural na cidade: Problemas e Desafios. In L. Rubim e N. Miranda (org.). Transversalidades da Cultura. Salvador: EDUFBA, 133- 179.

Ramos, N. (coord.) (2008). Educação, Interculturalidade e Cidadania. Bucareste: Milena Press.

Ramos, N. (2009). Diversidade Cultural, Educação e Comunicação Intercultural. Políticas e Estratégias de Promoção do Diálogo Intercultural. Revista Educação em Questão, (34), 20, CCSA, Natal, UFRN, 9- 32.

Ramos, N. (2009). Educar e formar na sociedade multi/intercultural - Contributos para a comunicação intercultural e cidadania. In N. Sobral, CONEXÓES - Educação, Comunicação, Inclusão e Interculturalidade. Porto Alegre: Redes Editora, 15-37.

Ramos, N. (2009). "Sociedades Multiculturais, Pedagogia Intercultural e Educação dos Migrantes e Minorias - Paradigmas e Desafios”. In H. Brutten e M. Paiva (org). Epistemologia das Ciências da Educação. Natal, EDUFRN, 133-158.

Samovar, L. \& Porter, R. (1988). Intercultural Communication. Belmont, Wordsworth Pub.

Sandercock, L. (2004). Reconsidering multiculturalism: towards an intercultural project. In Ph. Wood (ed.) Intercultural city reader (I). Bournes Green: Comedia.

Sassen, S. (2001). The global city. New York, Princeton: Princeton University Press.

Sef (2010). A população estrangeira residente em Portugal. Relatório de Imigração, Fronteiras e Asilo. Lisboa: SEF.

Todorov, T. (1988). Nous et les autres. Paris: Seuil.

Tourraine, A. (1997). Pourrons-nous vivre ensemble? Egaux et différents. Paris: Fayard.

Triandis, H. (1972). The analysis of subjective culture. New York: Wiley Interscience.

Unesco (2001). Déclaration Universelle sur la Diversité Culturelle. Paris: Unesco.

Unesco (2005). Convention sur la Protection et la Promotion de la Diversité des Expressions Culturelles. Paris: Unesco.

Unesco (2007). Dix clés pour la Convention sur la Protection et la Promotion de la Diversité des Expressions Culturelles. Paris: Unesco.

Vygotsky, L. (2001). Pensamento e linguagem. Vila Nova de Gaia: Estratégias Criativas.

Watzlawick, P. (1972). Une logique de la communication. Paris: Seuil.

Wieviorka, M. (1997). (dir.). Une société fragmentée? Le multiculturalisme en débat. Paris: La Découverte.

Wolton, D. (2003). L'autre mondialisation. Paris: Flammarion. 

Série Documentos

Imprensa da Universidade de Coimbra

Coimbra University Press

2011

- U

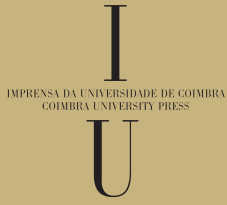

